\title{
Scar endometriosis-rare and painful entity: a case report
}

\author{
Anita Yadav ${ }^{1}$, Jyoti Baghel $^{1 *}$, Rajneesh Rawat ${ }^{2}$, Avinash Prakash ${ }^{3}$
}

\author{
${ }^{1}$ Department of Obstetrics and Gynecology, AIIMS Nagpur, Maharashtra, India \\ ${ }^{2}$ Department of General Surgery, GMC, Nagpur, Maharashtra, India \\ ${ }^{3}$ Department of Anesthesiology, AIIMS Nagpur, Maharashtra, India
}

Received: 09 March 2021

Accepted: 06 April 2021

\author{
*Correspondence: \\ Dr. Jyoti Baghel, \\ E-mail: bagheljyoti@aiimsnagpur.edu.in
}

Copyright: ( $)$ the author(s), publisher and licensee Medip Academy. This is an open-access article distributed under the terms of the Creative Commons Attribution Non-Commercial License, which permits unrestricted non-commercial use, distribution, and reproduction in any medium, provided the original work is properly cited.

\section{ABSTRACT}

Scar endometriosis is a rare type of extra-pelvic endometriosis that develops following obstetrical and gynecological surgeries. It is a rare entity, though probably on the rise, due to the increase in caesarean sections performed worldwide. This manuscript reports a rare case of scar endometriosis involving rectus sheath following repeat caesarean section and was managed at a tertiary level centre. The patient required surgical excision of the lesion and was kept on regular follow-up following surgery. The physiopathology of scar endometriosis is complex; its symptomatology is rich and diverse but detailed history, thorough clinical examination along with imaging and histopathological evaluation is usually efficient in diagnosing the condition.

Keywords: Endometriosis, Caesarean section, Scar endometriosis

\section{INTRODUCTION}

Endometriosis is defined as the presence of endometrial glands and stroma outside the uterine cavity. It is a major gynecological problem that affects $8-10 \%$ of women of reproductive age. ${ }^{1}$ Endometriosis is common in the pelvic organs like ovaries; pouch of Douglas, broad ligament, uterosacral ligament, fallopian tubes, rectosigmoid colon, bladder, and uterovesicle space, and also on other genital organs like episiotomy scars and bartholin glands. ${ }^{2}$ Extra pelvic endometriosis is a rare entity occurring in the following possible sites- in the order of their frequency: the peritoneum, the abdominal wall, and the bladder. Scar endometriosis is a rare entity. The majority of the cases have been reported after obstetrical or gynecological procedures such as caesarean delivery, hysterotomy, hysterectomy, episiotomy and tubal ligations. ${ }^{3}$ The reported incidence of scar endometriosis after caesarean section is $0.3-0.4 \%$ and the following hysterotomy is 1 $2 \% .^{4}$ Although rare, but with an increasing number of caesarean section this complication is not infrequent.

\section{CASE REPORT}

A 32-year-old multiparous lady, para 2 with 2 live issues with the complaint of cyclical abdominal pain for 1 year. She underwent a caesarean section 9 years ago followed by repeat caesarean 5 years back. She started developing swelling and cyclical pain last year followed by a gradual increase in the size of the swelling. On examination, she was found to be obese (BMI- $30.6 \mathrm{~kg} / \mathrm{m}^{2}$ ) with tenderness in the umbilical and hypogastric region.

On ultrasound, a heterogeneous hypoechoic lesion with significant internal vascularity of size $16 \times 9 \times 23 \mathrm{~mm}$ was noted in the right rectus sheath in the infra umbilical region. On MRI, a focal area of altered signal in the distal third of paramedian aspect of right rectus abdominis muscle in the infraumbilical region of size $20 \times 8 \times 22 \mathrm{~mm}$ suggestive of endometriosis.

She underwent resection of ectopic endometrial implants under spinal anesthesia which were subsequently sent for 
histopathological examination. The report confirmed scar endometriosis post-operative period was uneventful. A clinical follow-up and USG were done after two months. No abnormalities were detected.

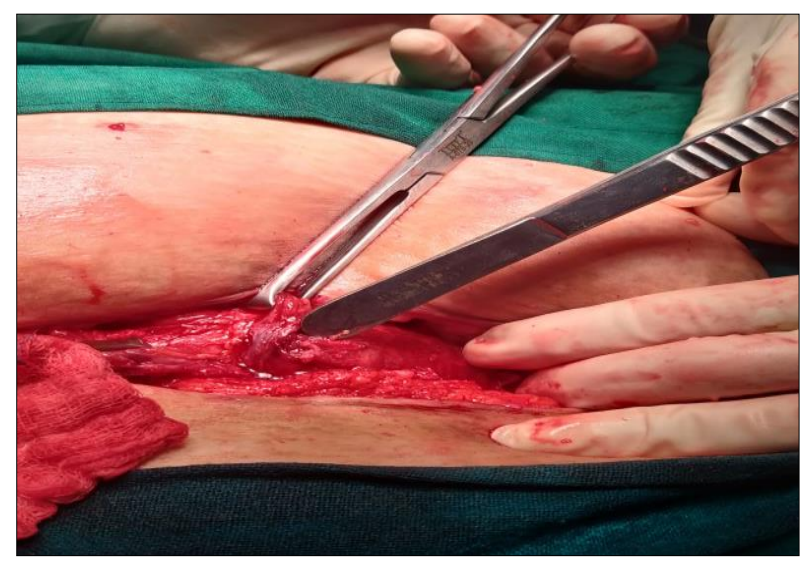

Figure 1: Intraoperative image showing rectus sheath with evidence of endometriosis at the time of excision.

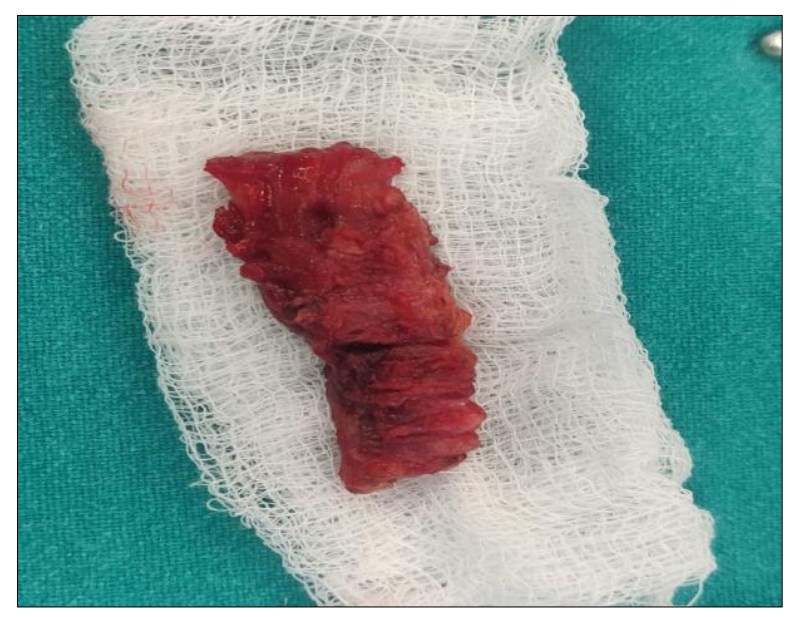

Figure 2: Resected segment of rectus sheath endometriosis.

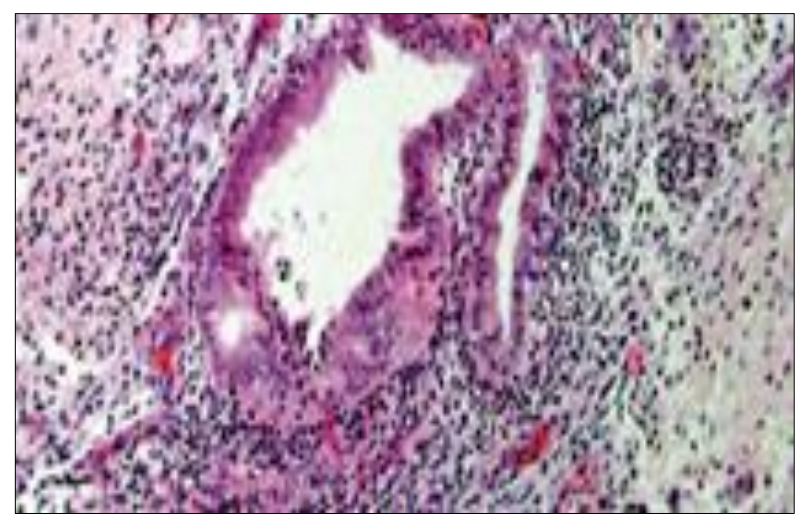

Figure 3: Histopathological examination of the resected segment showing endometrial glands and stroma.

\section{DISCUSSION}

Scar endometriosis is defined by the implantation or/and growth of endometrial tissue post-surgically at the incision site. It is a very rare entity. It affects $10-15 \%$ of fertile females; the most common age group is 25-35 years. ${ }^{5}$ Caesarean section delivery is a very common cause. It can be rarely seen following an appendectomy, episiotomy, laparoscopic procedures, and inguinal herniorrhaphy. ${ }^{6}$ The frequency of scar endometriosis is increasing these days because of the increase in caesarean section rates.

Various theories are postulated to explain the pathogenesis of endometriosis; however, the most accepted theory is the direct mechanical implantation of endometrial tissue on the scar site. Endometrial tissue directly implants into the caesarean section site and proliferates under the effect of estrogen. The strongest risk factor for the development of scar endometriosis is early hysterectomy like for hysterectomies for abortion. ${ }^{7}$ The endometrial tissue may reach the surgical scar through lymphatic or vascular routes, thereby giving rise to scar endometriosis.

The diagnosis of scar endometriosis may be very challenging. Various differential diagnoses which may mimic the similar presentation include desmoid tumor, suture granuloma, fat necrosis, fibrosis, nodular fasciitis, ventral and incisional and hernias, hematomas, abscesses, and primary or metastatic malignancies. Cyclical changes in the severity of pain and size of endometrial implants during menstruation are classically seen in endometriosis. The patient usually complains of pain on palpation and an elevated unsightly hypertrophied scar or lump. However, in the largest reported series to date, only $20 \%$ of patients had these symptoms. ${ }^{8}$ Various studies showed that time interval between surgery and onset of clinical features varied between 3 months to10 years, Biswas et al. reported clinical presentation after 5 years following caesarean section (LSCS). ${ }^{9}$ Celik et al reported a case with a 2 year's time interval. ${ }^{10}$

There are various methods for diagnosis of scar endometriosis such as ultrasonography, computed tomography, and magnetic resonance imaging. Imaging procedures help rather than confirm in obtaining an aforesaid differential diagnosis. The role of doppler sonography and fine-needle aspiration cytology (FNAC) is not much clear in the diagnosis of scar endometriosis. ${ }^{11}$ Histopathological examination is the investigation of choice for the diagnosis of scar endometriosis. It is diagnosed by the presence of endometrial glands, stroma, and hemosiderin pigment. In our case, clinical presentation and radiological features were suggestive of the diagnosis of caesarean scar endometriosis which was further confirmed by histopathological examination.

Therapeutic management mainly includes surgical excision with clear margins along with reconstruction of damaged tissue. Medical treatment involving hormone suppression has been suggested to relieve clinical 
symptoms but, according to Al-Jabri, it only gives partial relief, and recurrence after the cessation of medication is constant. ${ }^{12}$ Recurrence rates following surgery are variable but they are usually low.

No recurrence was reported by $\mathrm{Uc}_{3}$, ar et al. for a followup period ranging from 12 to 60 months. ${ }^{13}$ Horton et al. found a recurrence rate of $4.3 \%$, while Zhang and Liu reported a recurrence of $7.8 \%$ over an average period of 20 ( \pm 16$)$ months. ${ }^{14,15}$

\section{CONCLUSION}

Anterior abdominal wall scar endometriosis poses a challenge for diagnosis and treatment, because of varied manifestations and recurrence. The association of clinical symptoms with the menstrual cycles should clinch the diagnosis, and knowledge about the disease and strong clinical suspicion are needed to diagnose this condition.

Funding: No funding sources

Conflict of interest: None declared

Ethical approval: Not required

\section{REFERENCES}

1. Acién P, Velasco I. Endometriosis: a disease that remains enigmatic. ISRN Obstet Gynecol. 2013 Jul 17;2013:242149.

2. Machairiotis N, Stylianaki A, Dryllis G, Zarogoulidis $\mathrm{P}$, Kouroutou $\mathrm{P}$, Tsiamis $\mathrm{N}$, et al. Extrapelvic endometriosis: a rare entity or an under diagnosed condition? Diagn Pathol. 2013;8:194.

3. Sharma M, Nautiyal R, Chaturvedi J, Bhargava S. Scar endometriosis following caesarean section: a rare case report. Int J Reprod Contracept Obstet Gynecol 2015;4:884-6.

4. Chatterjee SK. Scar endometriosis: a clinicopathologic study of 17 cases. Obstet Gynecol. 1980;56(1):81-4.
5. Wolf Y, Haddad R, Werbin N, Skornick Y, Kaplan O. Endometriosis in abdominal scars: a diagnostic pitfall. Am Surg. 1996;62(12):1042-4.

6. Blanco RG, Parithivel VS, Shah AK, Gumbs MA, Schein M, Gerst PH. Abdominal wall endometriomas. Am J Surg. 2003;185(6):596-8.

7. Scott RB, Linde RW. Clinical external endometriosis; probable viability of menstrually shed fragments of endometrium. Obstet Gynecol. 1954;4(5):502-10.

8. Ding DC, Hsu S. Scar endometriosis at the site of cesarean section. Taiwan J Obstet Gynecol. 2006;45(3):247-9.

9. Biswas BK, Gupta N, Magon N. Incisional endometriosis: A rare cause for a painful scar - A report and commentary. Niger Med J. 2012;53(4):257-9.

10. Celik M, Bülbüloglu E, Büyükbese MA, Cetinkaya A. Abdominal wall endometrioma: Localizing in rectus abdominus sheath. Turk J Med Sci. 2004;34:341-3.

11. Pathan SK, Kapila K, Haji BE, Mallik MK, Al-Ansary TA, et al. Cytomorphological spectrum in scar endometriosis: a study of eight cases. Cytopathology. 2005;16(2):94-9.

12. Al-Jabri K. Endometriosis at caesarian section scar. Oman Med J. 2009;24(4):294-5.

13. Uçar MG, Şanlıkan F, Göçmen A. Surgical Treatment of Scar Endometriosis Following Cesarean Section, a Series of 12 Cases. Indian J Surg. 2015;77(S2):682-6.

14. Horton JD, Dezee KJ, Ahnfeldt EP, Wagner M. Abdominal wall endometriosis: a surgeon's perspective and review of 445 cases. Am J Surg. 2008;196(2):207-12.

15. Zhang J, Liu X. Clinicopathological features of endometriosis in abdominal wall--clinical analysis of 151 cases. Clin Exp Obstet Gynecol. 2016;43(3):37983.

Cite this article as: Yadav A, Baghel J, Rawat R, Prakash A. Scar endometriosis-rare and painful entity: a case report. Int J Reprod Contracept Obstet Gynecol 2021;10:2104-6. 